
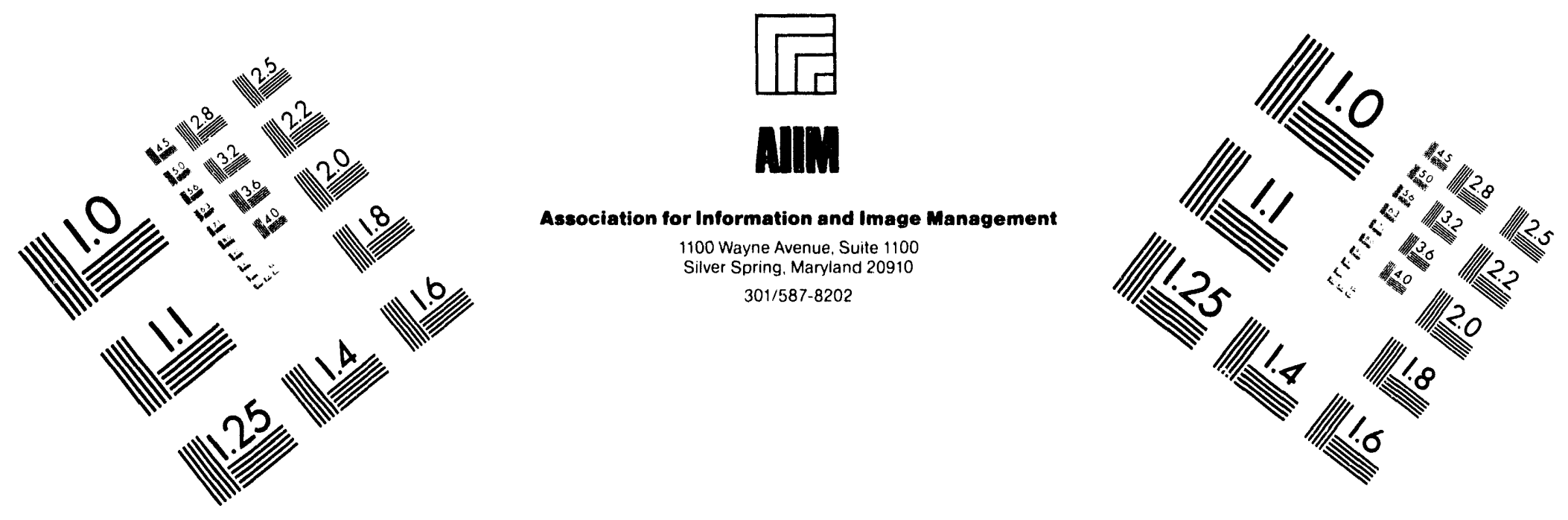

\title{
Centimeter
}

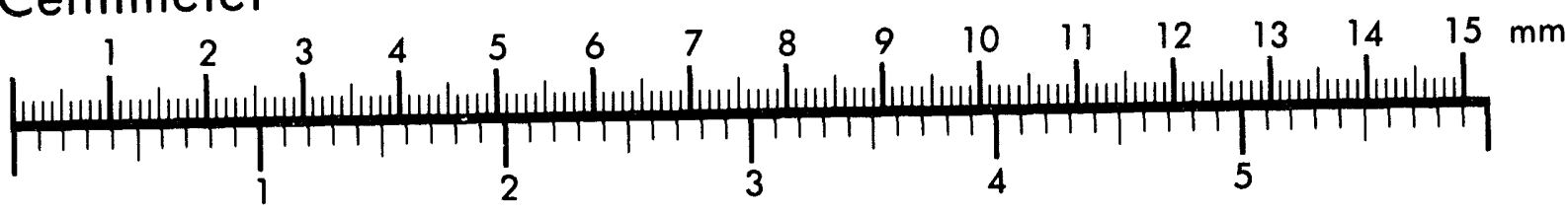
Inches



MANUFACTURED TO AIIM STANDARDS BY APPLIED IMAGE. INC.

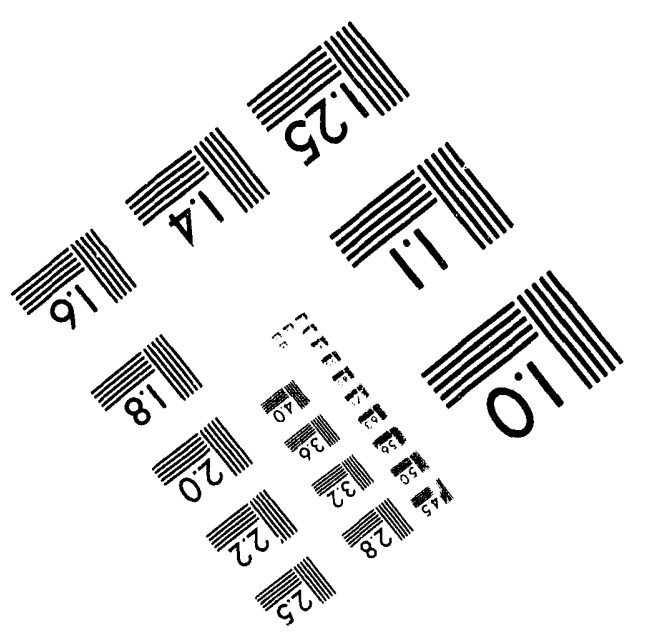



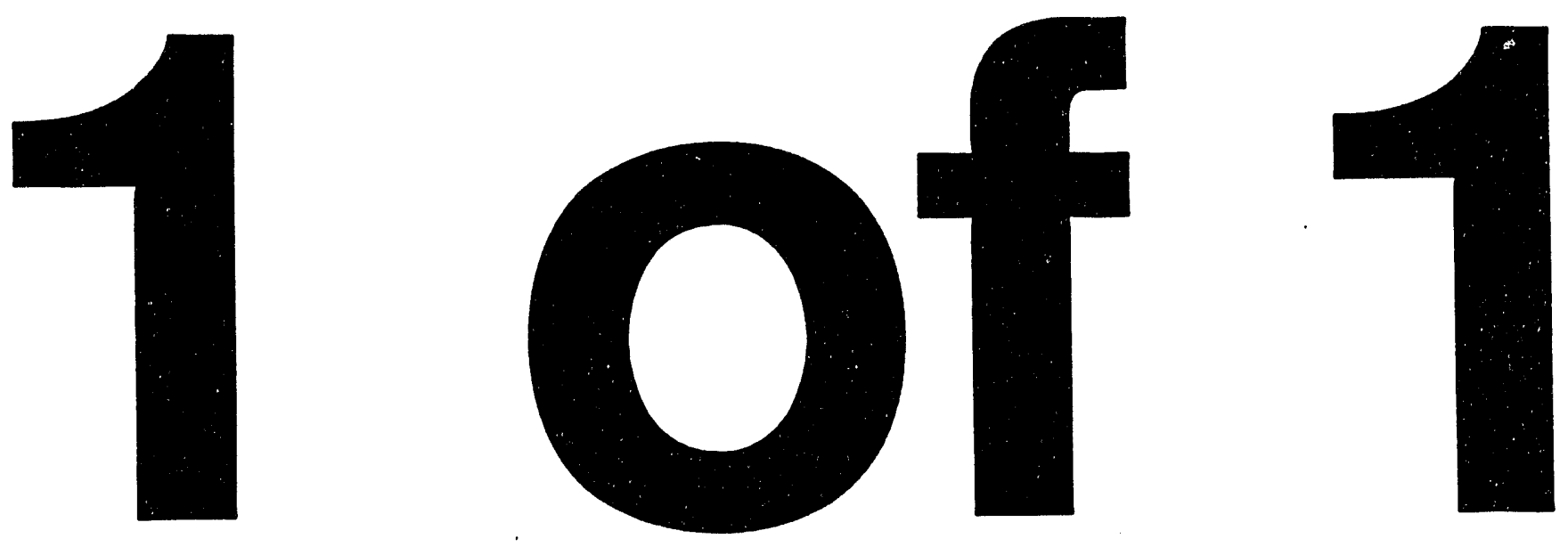

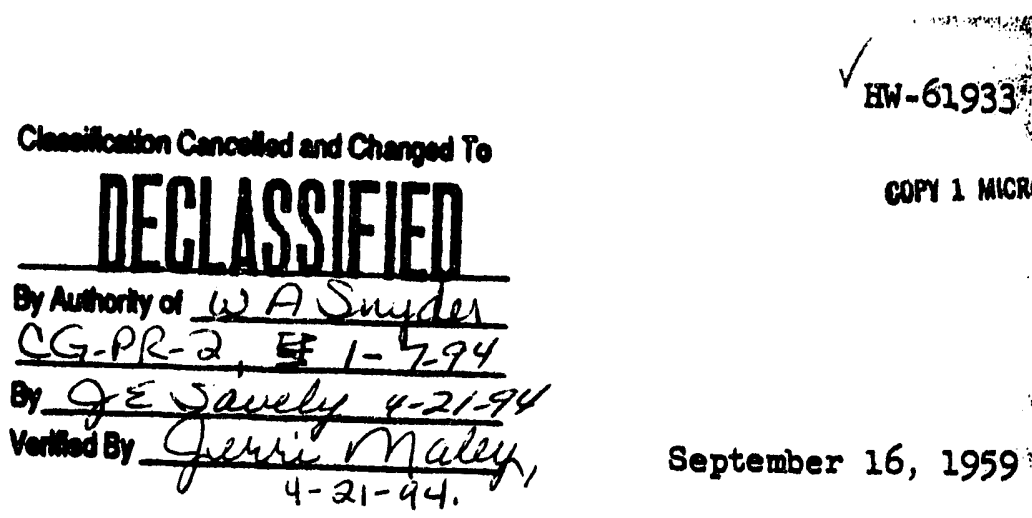

U. S. Atomic Energy Commisaion

Banford Operations office

Richland, Washington

Attention: Mr. M. B. Arndt, Chlef, Special Projects Branch

Procese Engineering and Menufacturing Division

Gentlemen:

\section{IMFORMATION IN SUPPORT OF THE FPC STUDY}

Three of the 1tems of Information you have requested in connection with the FPC study are transmitted hereln.

\section{Table of Predicted Life Expectancy of the 105-N Reactor}

A table of predicte 1 life expectancy for cases in addition to those covered In the letter of J.1ly 30, 1959, to Mr. J. E. Trav18, on the same subject, is attached. The predicted lives shown for some of the cases are somewhat higher than those which you had arrived at by interpolation between the points in the referenced letter because of temperature effects on the graphite. There 1s some difference in lifetime between, for example, a case lavolving $2800 \mathrm{mw}$ maximum power operating throughout the year at an average $1400 \mathrm{mw}$ and one $1 \mathrm{n}-$ volving $2800 \mathrm{mw}$ operating for $1 x$ months and shut down for the remalning $81 x$. Both cases would have an average annual plant factor of .50 , but the distort1on of the graphite vould be greater in the latter case. This table was prepared on the basis of the former method of operation--that 1s, longer period of operation at lower powers to echleve a given plant factor.

It is again emphasized that the variety of numbers given in this table does. not indicate that the reactor life can be predicted with a degree of prec1sion of one, two, or three yeare out of 30 . They are to be contiddered" only: as numbers within the range previously indicated that can be used in this study to arrive at the relative economica of the several cases.

\section{Steam Generat1on Transiente Politowling a Scram}

As you have requested, ten copleg of a curve showlag heat rate versus time following a reactor scram are at tached.

You w1ll real1ze that the date how th these curves arei prelifininary, but

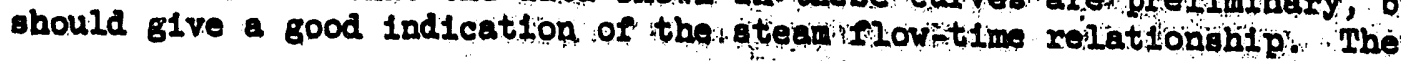

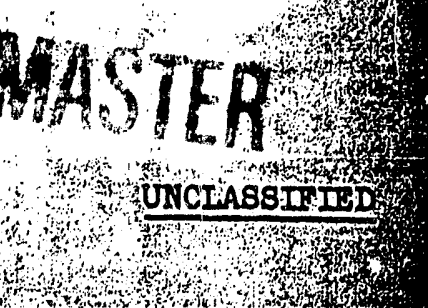


design of the plant has not progressed to the polat where the extent oi the bypaseing of primary coolant around the evaporators bas been determined, but it 1. expected that 1t w1ll be between the zero and one-th1rd values shown on the chart, probably closer to the one-thled flow value.

\section{Sot1mated Number of Outages}

The following table gives opecific numbers for scbeduled outages and target unecheduled outages under the varlous conditions of plant factor and fuel exposure level for both dual-purpose and power-only operation. In the duslpurpose operation the average plant factor 18 assumed to be 80 percent and estimates are shown for 70 and 100 percent of goul ruel exposure. For the power-only condition, three sets of numbers are g1ven, 50, 80 , and 100 percent average plant factor, all at fuel exposure levels of $10,000 \mathrm{mwd} / \mathrm{T}$. In th1. table the aumbers for maximum thermal power assume that some meane w1Il be ut1lired, such as burnable polsons in the fuel elements, to extend the Interval between refuelinga. As discussed between us, no detalled work has been performed on exactly how this might be accomplished, or what extra fuel costs might be 1nvolred; but 1t 1 our opla1on that 1 t will not be a difficult matter to extend the period between reruelings to the extent shown, at a nomInal cont. The values shown for the 40 percent thermal level do not assume any burabible poison in the ruel; those at the 60 percent thermal level assume a small ut1lization of burnable polson.

The extent to which such means will be employed w1ll, of course, depend upon conditions at the time and on the magnitude of the incentive to extend periode between refueling at sowe extra ruel cost.

Dual-Puxpose - .80 Plant ractor

Scheduled Target Unschoduled All

Power-0aly - At 10,000 wed/I $\frac{\text { Percent Coal Exposure }}{100}$

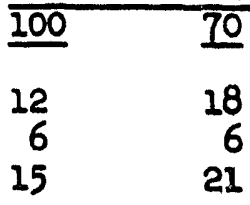

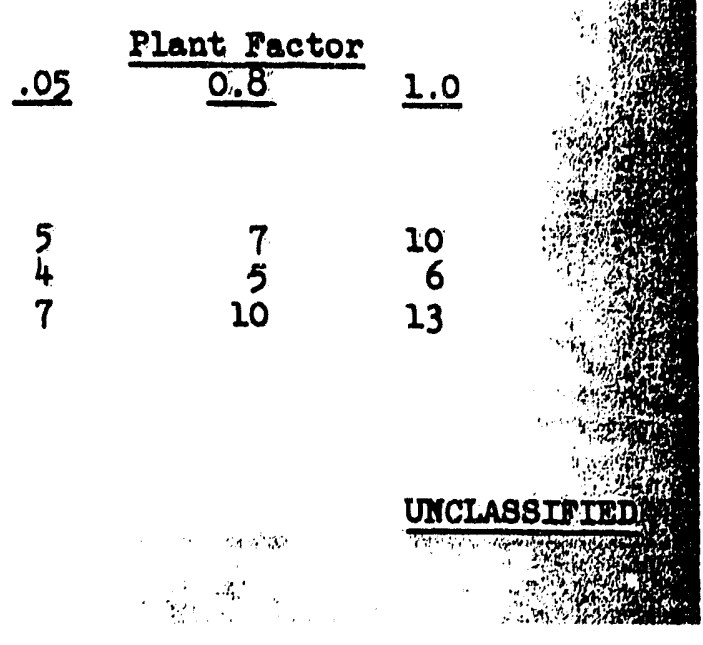

$04 / 20 / 1994$ 


\section{Percent Thermal}

\section{Scheduled}

Target Unscheduled

All

40 Percent Thermal

Scheduled

Target Unscheduled

All $\frac{\text { Plant Fector }}{0.8} \quad 1.0$

$\begin{array}{rrr}5 & 7 & 10 \\ 4 & 5 & 6 \\ 7 & 10 & 13\end{array}$

Very truly yours,

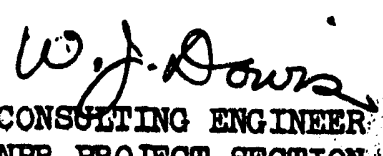

NPR PROTECT SECTION:

WJ Dow1s:bem

Attachmente - 2

cc: J Krema

DJ O 'Ne1l

CR Qualbeim

H耳 Sch1pper

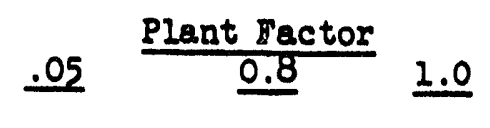


U. 85 Alomil Energy

bee GH Brown
DL Condotte
RL Dickeman
IM Kratz
WH MeIntoih
WJ Dowls - 2
Records Center
300 F1le




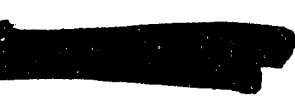

UNDOCUMAHNYHD:

HW-61933

PRESICLED LIFE EXPECTANCY OF THE 105-N REACTOR

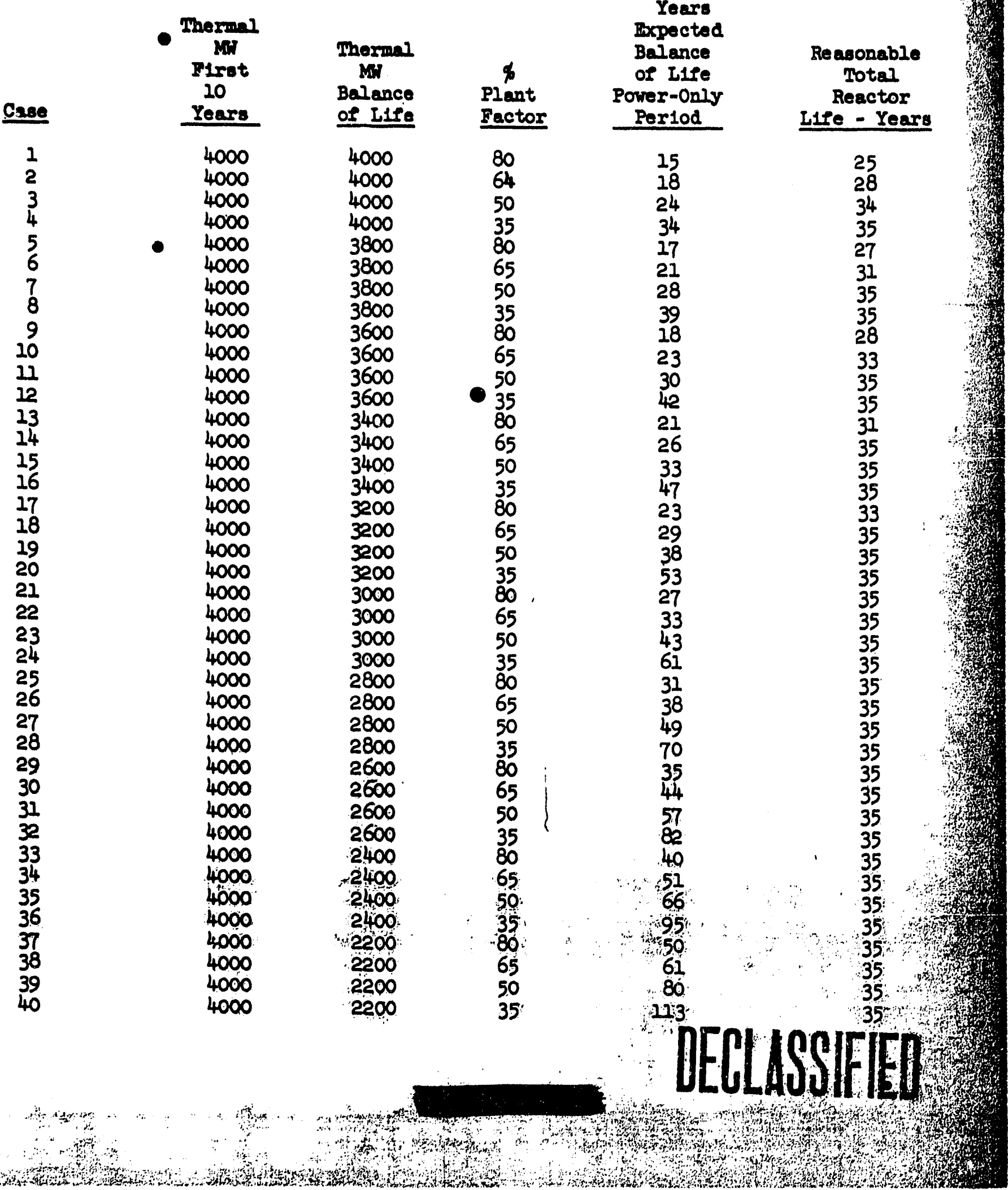




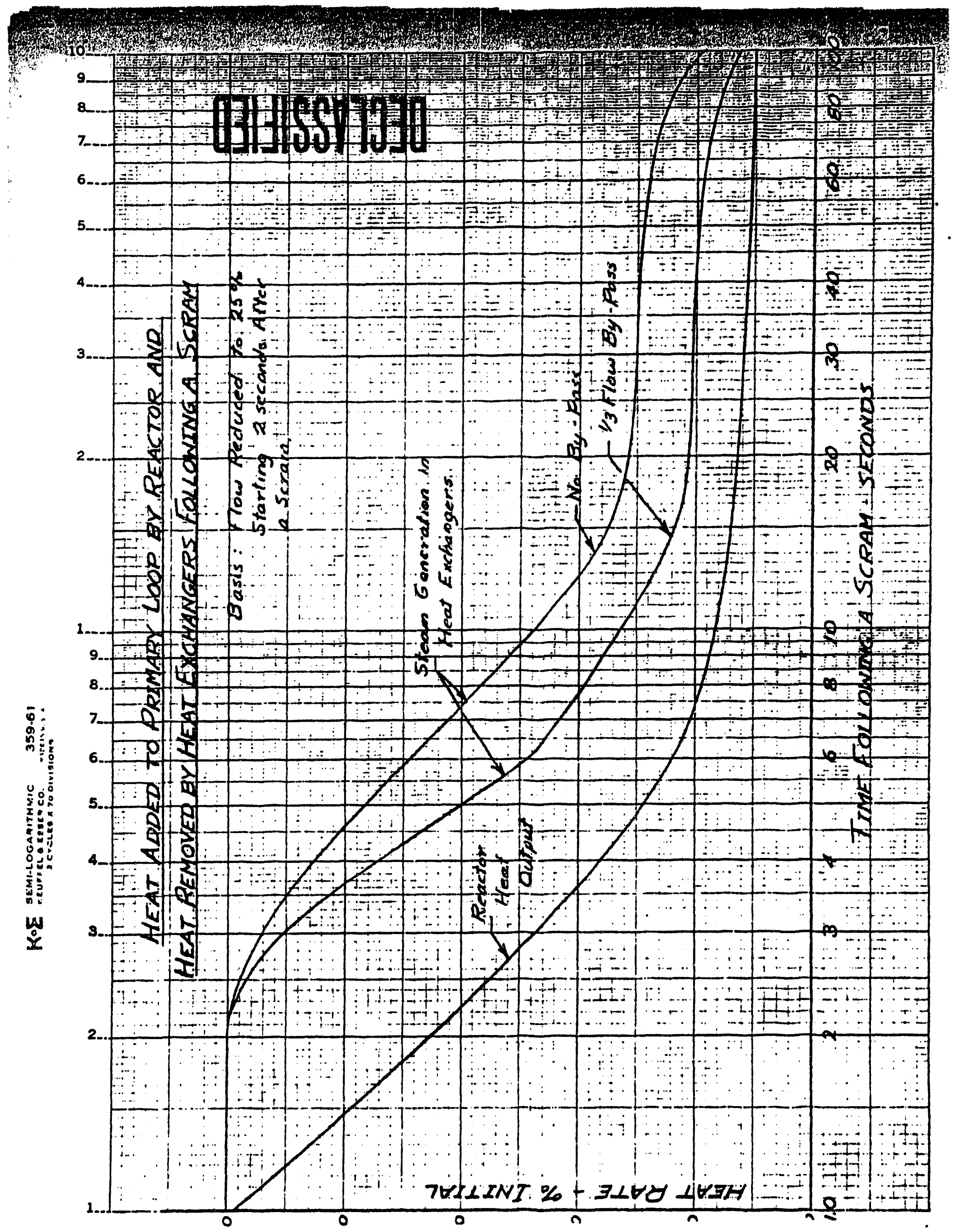



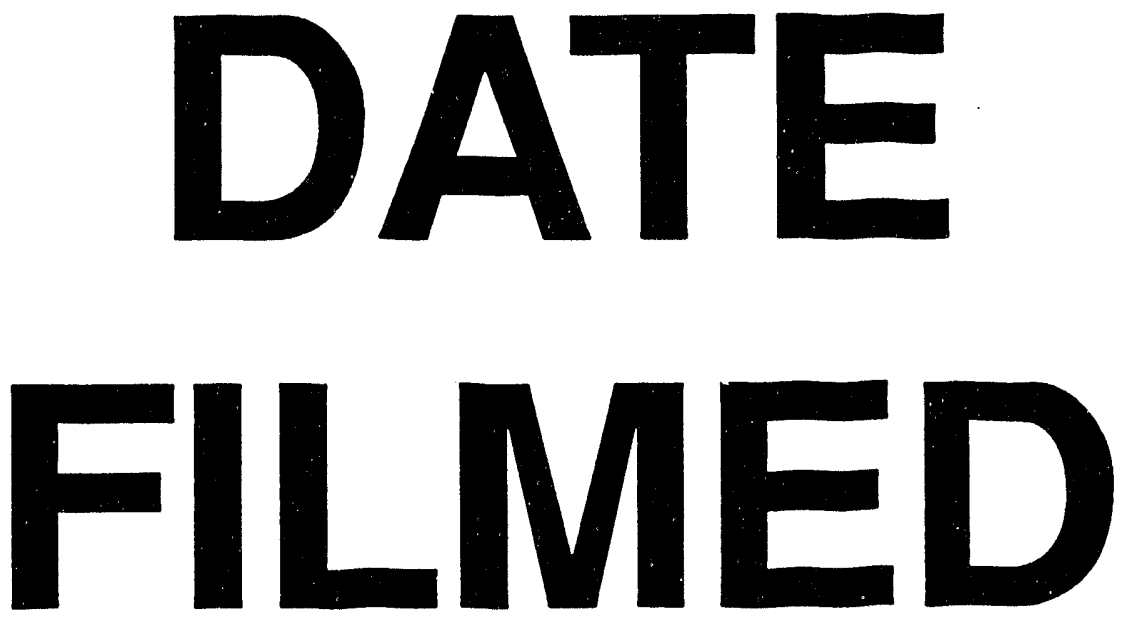

$10 / 20 / 94$
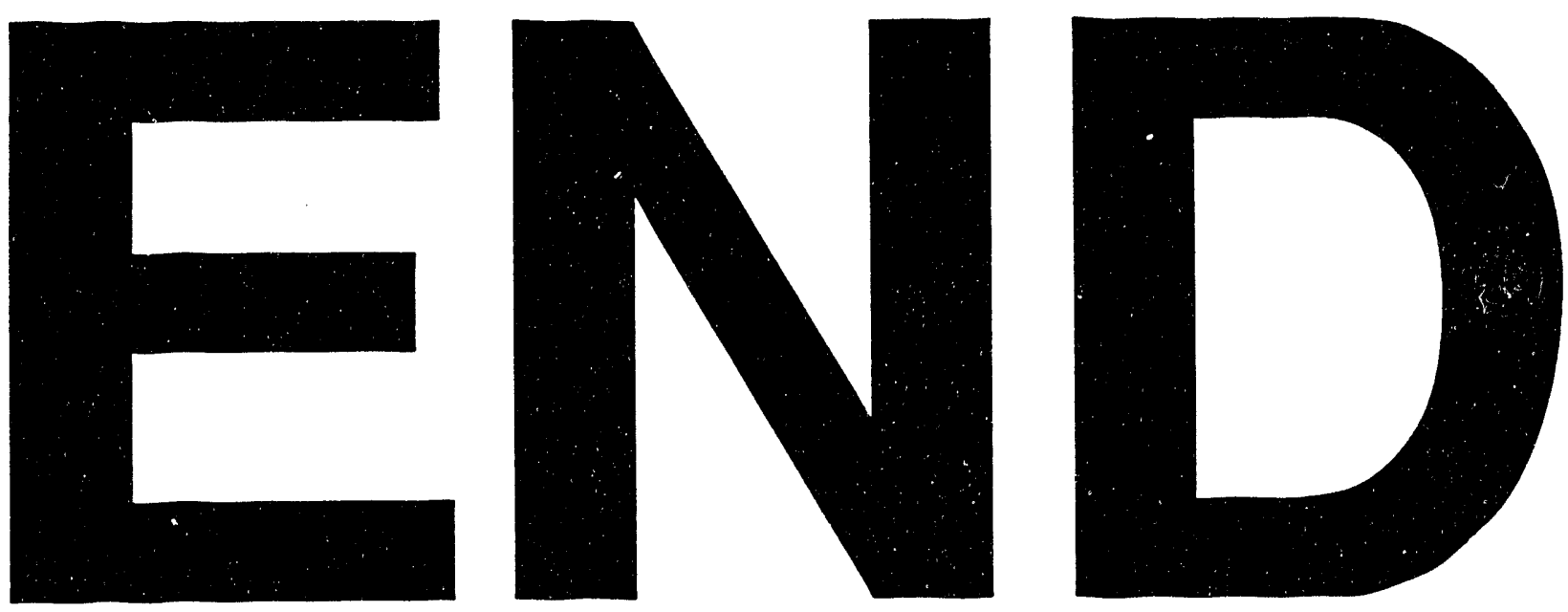
